\title{
Reconstruction Method of Landscape Planning Mode based on VR Technology and Wireless Communication Technology
}

\section{Hang Yao}

Anhui Agricultural University

\section{Yan Jiang}

Zhejiang Jinhua Science and Trade Vocational and Technical College

Rongqing Yang ( $\nabla$ yangrq1102@163.com )

Anhui Agricultural University

\section{Research Article}

Keywords: virtual reality technology, wireless communication technology, landscape planning, Landscape Design, Artificial Intelligence

Posted Date: April 26th, 2021

DOI: https://doi.org/10.21203/rs.3.rs-433131/v1

License: (c) (i) This work is licensed under a Creative Commons Attribution 4.0 International License. Read Full License 


\title{
Reconstruction method of landscape planning mode based on VR technology and wireless communication technology
}

\author{
YAO Hang ${ }^{1}$, JIANG Yan ${ }^{2}$, YANG Rongqing ${ }^{1 *}$ \\ 1.College of Light Textile Engineering and Art, Anhui Agricultural University, Hefei \\ 230000, China \\ 2. Department of Tourism and Arts, Zhejiang Jinhua Institute of Science and Technology, Jinhua \\ 321019, China \\ Corresponding Author's E-mail: yangrq1102@163.com \\ YAO Hang ${ }^{1}$ and JIANG Yan ${ }^{2}$ contributed equally to this work. They are co-first authors
}

\begin{abstract}
With the increasing complexity of human settlements and the deterioration of the ecological environment, landscape design shoulders the arduous responsibility. However, due to various reasons, the digital process of landscape planning and design has lagged behind the times. This paper discusses the difficulties of artificial intelligence reconstruction design in current landscape design, and points out the necessity of promoting artificial intelligence reconstruction design in landscape design. This paper defines the definition, characteristics and concept pedigree of landscape architecture artificial intelligence reconstruction design, analyzes the main digital design methods and application software platform in the concept pedigree, and summarizes the flow chart of landscape architecture artificial intelligence reconstruction design based on VR technology and wireless communication technology. Finally, the limitations and misunderstandings of current AI reconfiguration design are analyzed.
\end{abstract}

Key words: virtual reality technology; wireless communication technology; landscape planning; Landscape Design, Artificial Intelligence

\section{Introduction}

The process of landscape planning not only needs the comprehensive analysis, reconstruction and expression of the objective elements such as geography, ecology, climate, topography, hydrology, plants, site, landscape, traffic, buildings and residence, but also needs to produce different art forms to carry and describe the specific semantic value and humanistic value of landscape architecture. In the past research, the software based on computer graphics represented by AutoCAD, Photoshop and 3dsmax, because of its fast, efficient, easy to modify, storage and other characteristics, quickly replaced the drawing board, t-ruler and stylus, became the standard equipment of landscape planning and design, and formed a wrong concept - these three software represent the so-called "computer-aided design" ” 。 AutoCAD, Photoshop, 3dsmax and other software only replace the hand-painted working mode at the back end of the planning and design process [3]. They can make the drawing more accurate, more beautiful and more realistic, but they can't make the design more scientific, more reasonable and more creative. That is to say, they are only computer-aided drawing, not aided design - computers can not help designers to draw more accurately in a broader field, think deeply and cooperate. The future era is digital and information age. Due to the rapid development of wireless communication ability and digital technology, human beings have unprecedented ability to deal with complex problems in complex environment. In architecture, urban and rural planning and other related fields, digital technologies such as parametric modeling, wireless communication algorithm and virtual reality have been applied to all aspects of subject industry. Therefore, this paper proposes landscape planning based on VR 
technology and wireless communication technology The method of landscape planning pattern reconstruction applies VR technology and wireless communication technology to specific objects to provide reference for landscape planning pattern reconstruction.

\section{$1 \mathrm{AI}$ reconstruction method of landscape planning pattern}

\subsection{Landscape architecture pattern planning}

In order to apply virtual reality technology to landscape planning and design, there are still some technical problems: it is difficult to realize the establishment and real-time rendering of complex landscape 3D model. It is difficult to realize the immersion of user interface in VR system. In terms of hardware, the speed of data storage equipment is slow, the capacity is very insufficient, and the expensive cost of display equipment and its display clarity and other problems ${ }^{[5]}$. The three basic characteristics of virtual reality technology can be represented by a triangle as shown in the figure: interaction, immersion and conception. The first technique is to interact with the virtual device, such as observing the characteristics of the natural environment in real time ${ }^{[6]}$. The second feature is immersion, which enables participants to have a real sense of being on the scene. This is a feature based on the real-time of many senses (vision, hearing, touch and smell). Third, virtual reality technology enables people to get perceptual and rational knowledge from the environment of qualitative and quantitative comprehensive integration and massive data through many technical means, which further stimulates creative thinking ${ }^{[7]}$. Based on this, the landscape pattern planning features under VR technology are designed as follows:

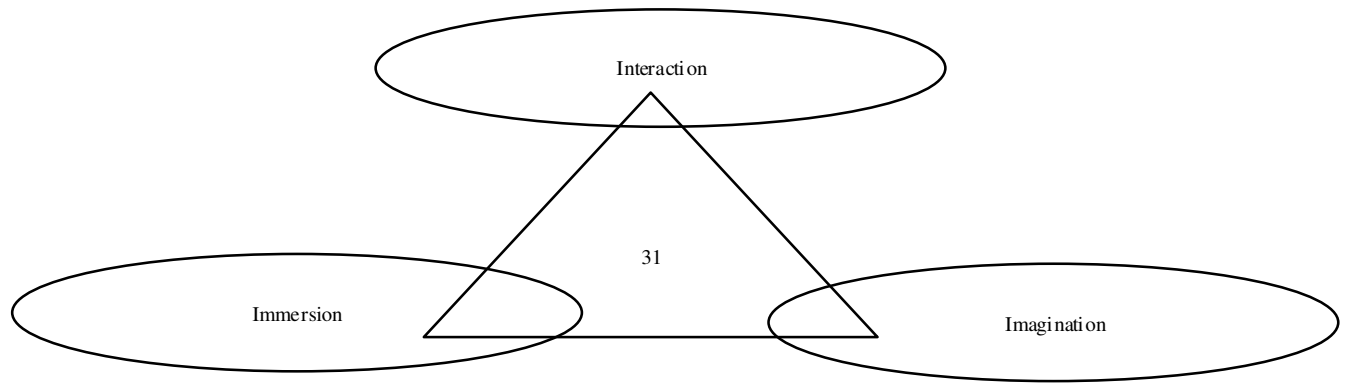

Fig. 1 Landscape architecture pattern planning characteristics under VR technology

The performance of VR technology in landscape architecture planning and design only stays in the roaming stage of "having a look", and most of them lack the dynamic shaping of landscape and the display of landscape culture. Not pay attention to show the "people-oriented" principle of garden green space and garden $\operatorname{art}^{[8]}$. No information query function. The application of VR technology in landscape architecture planning and design has not got rid of the misunderstanding of "pure visual performance", ignoring the application of VR technology in all stages of landscape architecture design and creation, public participation in landscape architecture, disaster prevention of public green space, landscape teaching and other aspects. VR technology is not integrated with geographic information system and network, leading to the advantages of VR technology not fully play out, let alone achieve the integration of integrated information system ${ }^{[9]}$. For the virtual reality technology software based on graphics, its criteria can be divided into four categories, and each category can be divided into several single indicators. Of course, the specific software can be increased or decreased according to its emphasis, here only consider the general situation ${ }^{[10]}$. According to the determined evaluation index, the hierarchical structure as shown in the figure is established. 


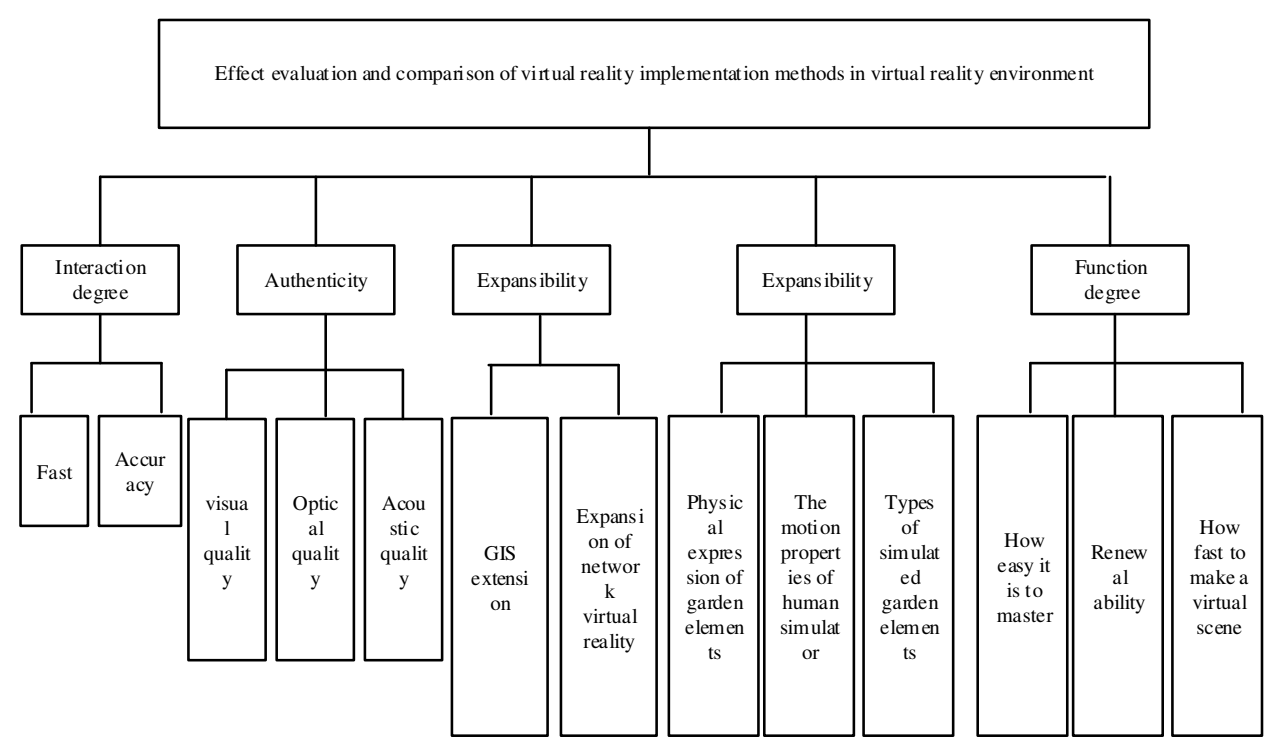

Fig. 2 Hierarchical structure of landscape architecture pattern planning effect comparison

Nowadays, the development of computer and information technology is changing day by day, and new software platforms emerge endlessly ${ }^{[11]}$. And the related fields such as architectural design and urban and rural planning, digital design methods and technologies are also rising and rising, in the stage of comprehensive promotion and deepening application, which provides the best opportunity for the digital development of landscape planning and design ${ }^{[12]}$. Based on the research results of other related fields, the author combs the main concepts and methods of digital design, classifies and classifies them, and forms a preliminary but clear concept spectrum chart of AI reconstruction design of landscape architecture. In order to clarify the main AI reconstruction design methods and application fields, it also makes a relatively accurate definition and pedigree of complex digital concepts, and gives a brief introduction to the future. Because vector graphics technology is adopted, the space occupied is very small and interactive ${ }^{[13]}$. Only a small space is needed to achieve high-quality animation effect, which is suitable for the demand of various network bandwidth and support flow technology. If the control is good, the download process is not felt ${ }^{[14]}$. Based on this, the landscape planning pattern reconstruction system is optimized as follows: 


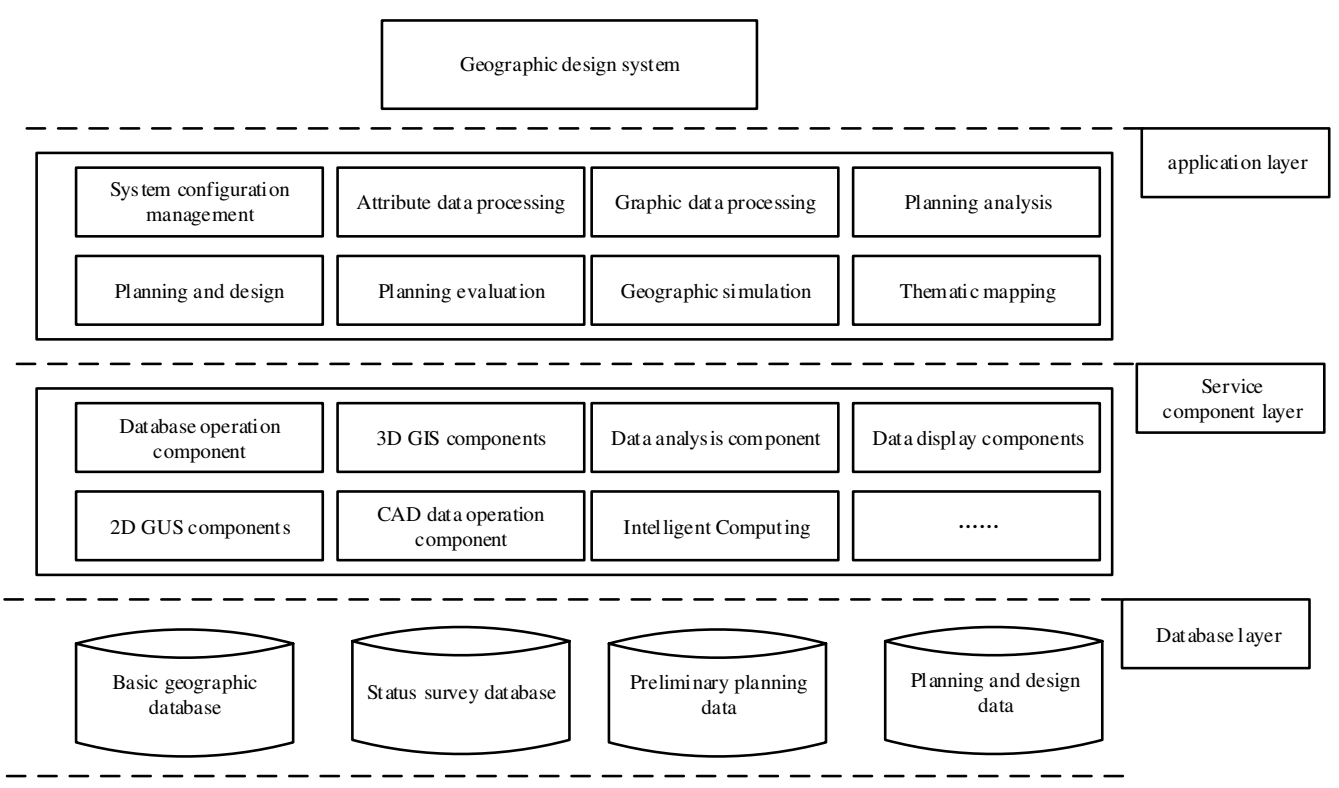

Fig. 3 Landscape architecture planning pattern reconstruction system

The concept and method application of landscape planning reconstruction has gone beyond the scope of landscape architecture, urban and rural planning, architecture, geography and civil engineering, and put forward a new way to solve the problems of planning and design ${ }^{[15]}$. The digital planning management information system based on VR technology can realize the management, maintenance and inquiry of current data and planning and design results, which is conducive to improving office efficiency and providing data database for subsequent planning and design ${ }^{[16]}$. At present, the field of landscape planning and design is mainly used in the planning and management of green space system, especially in the management of scenic spots. The database design of landscape planning and management information system includes basic data partition, green space data classification and green space coding ${ }^{[17]}$. The data partition is to divide the green space in the region according to the administrative boundary, and then further classify the green space according to the situation of the ownership units of the green space, so as to be the basic management unit of the management information system.

\subsection{Evaluation algorithm of landscape architecture planning pattern reconstruction}

To establish a complete landscape architecture AI reconstruction design system, we need to define its basic concept first: Landscape Architecture AI reconstruction design is to build the whole process of landscape architecture planning and design on the digital platform, rely on the computer computing ability and graphics ability, scientifically analyze and evaluate the space environment, rationally construct objective and rigorous design logic, and increase the designer to deal with complex environment The ability and creativity of environment and design object to solve problems and express the media with more experience and authenticity will eventually produce landscape design achievements with scientific, artistic and social value ${ }^{[18]}$. The whole cycle process of landscape architecture planning and design includes the following main links: information acquisition - Environmental Analysis - design construction design evaluation design modification deepening design expression medium. AI reconfiguration design needs to be deeply involved in every link of planning and design, and establish a complete digital design strategy ${ }^{[19]}$. Digital information runs through the whole design cycle, and multiple software platforms exchange information and data with each other, so that the planning and design links can be 
smoothly connected, which makes the design from environmental cognition to final completion, and is always based on a relatively objective, fast, efficient and intuitive design system. The system should present network structure, which can form a multi route circular digital design path, form a complete data ring and work chain, and realize network collaborative design and deep connection and cooperation of multiple types of work. According to the different physical conditions such as the location of the plants and the function of landscape making, there are many necessary requirements for the size of landscape landscape ${ }^{[20]}$. In order to create a good landscape plant ecological environment, it is necessary to measure and calculate the specific dimension parameters of all plant landscapes, that is, the calculation of landscape topography size. Only in this way can the planning effect of landscape be supported by a large number of data in the process of subsequent ecological environment configuration. Therefore, the first step of system establishment is to collect the 3D construction of landscape A large number of data are needed, including topographic and geomorphic data, vegetation coverage data, environmental climate data, sound change data, river and lake data, and surrounding building layout data. Therefore, the data acquisition equipment needed mainly includes VR technology, sensor, GPS and VR technology to launch laser beam to the ground ${ }^{[21]}$, and then calculate the distance from VR technology to the ground by pulse distance measurement according to the reflected laser beam, so as to get the landscape, river and lake and surrounding building layout of the landscape construction area. The principle formula of pulse ranging method is as follows:

$$
Y=\frac{1}{2} v \cdot t
$$

In the formula, $Y$ is the distance from VR technology to the surface of landscape planning area; $v$ is the propagation velocity of pulse laser $t$ is the time difference, accurately determine the location of the relevant green plants, greatly improve the physical work efficiency at the same time, high-quality completion of the garden ecological landscape configuration operation. Set up $f$ represents the ecological allocation coefficient of landscape plants, $w$ represents the terrain placement vector of plant landscape in the regional environment.

$$
R=\frac{f}{2} \sqrt{w p^{i}+q^{2}}
$$

Among them, ${ }^{p}$, represents the adaptability parameters of two different landscape plants to landscape topography, ${ }^{i}$ represents the application of power term coefficients. Plant ecological planting slope is a defined physical quantity related to the landscape environment configuration, which can limit the most suitable greening landscape plants in the fixed area of the garden. From the past experience of landscape ecological configuration, the vast majority of green plant landscape prefer slightly steep planting slope, and the ecological environment is relatively open, which can fully meet the demand of plant photosynthesis for water, sunlight, air and other physical factors, and this kind of ecological planting slope condition will be directly affected by the landscape terrain size. Generally, green plant landscape is more suitable The larger the terrain size of the landscape, the greater the ecological planting slope of the species, and vice versa .Set up $\lambda$ represents the ideal planting conditions of landscape plants. The simultaneous formula can express the ecological planting slope conditions of landscape as follows: 


$$
D=\frac{\sqrt{(y-1)|\lambda \cdot \bar{k}|}}{R^{2}}
$$

Among them, $y$ represents the basic configuration parameters of landscape ecological environment, $\bar{k}$ represents the ideal planting amount of landscape plants. The relative importance of each index is analyzed. According to the analytic hierarchy process, the judgment matrix is constructed hierarchically, and then the relative weight of each index is calculated, and each level is sorted. The five evaluation criteria of software evaluation target are interaction degree, authenticity degree, extension degree, function degree and usage degree. The judgment matrix, relative weight and hierarchical ranking of each criterion relative to the overall objective are shown in the table.

Table 1 Criteria for evaluation objectives

(CI=0.07 $<0.1$, in conformity with the requirements of conformity test)

\begin{tabular}{cccccccc}
\hline evaluate & $\begin{array}{c}\text { Interaction } \\
\text { degree }\end{array}$ & $\begin{array}{c}\text { Authen } \\
\text { ticity }\end{array}$ & $\begin{array}{c}\text { Function } \\
\text { degree }\end{array}$ & Usage & $\begin{array}{c}\text { Expans } \\
\text { ibility }\end{array}$ & $\begin{array}{c}\text { Relative } \\
\text { weight }\end{array}$ & $\begin{array}{c}\text { Hierarchical } \\
\text { sorting }\end{array}$ \\
\hline $\begin{array}{c}\text { Interaction } \\
\text { degree }\end{array}$ & 1 & 6 & 5 & 7 & 7 & 0.581 & 1 \\
$\begin{array}{c}\text { Authenticity } \\
\text { Function }\end{array}$ & $1 / 6$ & 1 & 3 & 5 & 4 & 0.206 & 2 \\
degree & $1 / 5$ & $1 / 3$ & 1 & 3 & 3 & 0.113 & 3 \\
Usage & $1 / 7$ & $1 / 5$ & $1 / 3$ & 1 & 1 & 0.051 & 4 \\
Expansibility & $1 / 7$ & $1 / 4$ & $1 / 3$ & 1 & 1 & 0.049 & 5 \\
\hline
\end{tabular}

Ecological efficiency is one of the main functions of landscape architecture. The statistical analysis software of landscape ecology, such as FRAGSTATS and pc-ord, can be used to analyze the data of large-scale landscape areas closely related to nature, and VR technology can be used to collect and manage the data. Netlogo, a script language integrated platform of computer modeling and simulation, can simulate the metabolism and evolution process of ecosystem in computer by using the prepared script of ecological dynamic evolution. The two indexes under the interaction criterion are fast and accurate. The fast measure is the real-time rendering speed. The accurate measure is to capture one frame of image to see the degree of distortion relative to the modeling model. The judgment matrix, relative weight and hierarchical order are shown in the table.

Table 2 Indicators of interaction criterion

(CI $=0.00<0.1$, meeting the requirements of consistency test)

\begin{tabular}{ccccc}
\hline Interaction degree & fast & accuracy & Relative weight & Hierarchical sorting \\
\hline fast & 5 & 1 & 0.833 & 1 \\
accuracy & 1 & $1 / 5$ & 0.167 & 2 \\
\hline
\end{tabular}

The purpose of landscape planning and design is to allocate outdoor space reasonably. In the traditional planning and design, the problem of paying more attention to the interface than to the space is very prominent. The space analysis is only a few so-called penetration lines and axes. Using digital tools, space can be evaluated and quantified. Using the relevant tools developed by the theory of spatial horizon and spatial syntax, such as Depthmap, we can reveal the spatial accessibility and organization logic, predict the human visual perception in space and the possible movement trend caused by it, and evaluate and judge the parameters such as integration and 
connectivity by computer. The index under the criterion of authenticity is reality, which is mainly used for comprehensive resolution evaluation. The judgment matrix, relative weight and hierarchy are shown in the table.

Table 3 Indicators of authenticity criteria

$(\mathrm{CI}=0.00<0.1$, meeting the requirements of consistency test $)$

\begin{tabular}{cccc}
\hline Authenticity & real & Relative weight & Hierarchical sorting \\
\hline real & 1 & 1 & 1 \\
\hline
\end{tabular}

The three indexes under the criterion of functional degree are the physical expression of landscape elements (reference index: the fidelity of landscape elements expression, including dynamic expression), the life cycle of landscape elements and the type of simulated landscape elements (reference index: the number of types of landscape elements). The judgment matrix, relative weight and hierarchy are shown in the table.

Table 4 Indicators of functional criteria

\begin{tabular}{cccccc}
\multicolumn{5}{c}{$(\mathbf{C I}=\mathbf{0 . 0 0 6 6 9}<\mathbf{0 . 1}$, meeting the requirements of consistency test $)$} \\
\hline Function degree & $\begin{array}{c}\text { The motion } \\
\text { properties of } \\
\text { human simulator }\end{array}$ & $\begin{array}{c}\text { Physical } \\
\text { expression of } \\
\text { elements }\end{array}$ & $\begin{array}{c}\text { Simulation } \\
\text { element type }\end{array}$ & $\begin{array}{c}\text { Relative } \\
\text { weight }\end{array}$ & $\begin{array}{c}\text { Hierarchical } \\
\text { sorting }\end{array}$ \\
\hline $\begin{array}{c}\text { The motion } \\
\text { properties of } \\
\text { human simulator } \\
\begin{array}{c}\text { Physical } \\
\text { expression of } \\
\text { garden elements } \\
\text { Types of }\end{array}\end{array}$ & 1 & 7 & 3 & 0.669 & 1 \\
$\begin{array}{c}\text { simulated garden } \\
\text { elements }\end{array}$ & $1 / 7$ & 1 & 3 & 0.088 & 3 \\
\hline
\end{tabular}

The three indicators under the usage index are the degree of difficulty in mastering, the scalability of the model and the updating ability. The judgment matrix, relative weight and hierarchy are shown in the table.

Table 5 Indicators of usage criteria $(\mathrm{CI}=0.06<0.1$. Meet the requirements of consistency test $)$

\begin{tabular}{cccccc}
\hline Usage & $\begin{array}{c}\text { How easy } \\
\text { it is to } \\
\text { master }\end{array}$ & $\begin{array}{c}\text { Interface and } \\
\text { upgrading } \\
\text { capability }\end{array}$ & $\begin{array}{c}\text { How fast to } \\
\text { create a } \\
\text { virtual scene }\end{array}$ & $\begin{array}{c}\text { Relative } \\
\text { weight }\end{array}$ & $\begin{array}{c}\text { Hierarchical } \\
\text { sorting }\end{array}$ \\
\hline $\begin{array}{c}\text { How easy it is to } \\
\text { master }\end{array}$ & 1 & 5 & 7 & 0.731 & 1 \\
$\begin{array}{c}\text { Interface and } \\
\text { upgrading capability }\end{array}$ & $1 / 5$ & 1 & 3 & 0.188 & 2 \\
$\begin{array}{c}\text { How fast to create a } \\
\text { virtual scene }\end{array}$ & $1 / 7$ & $1 / 3$ & 1 & 0.081 & 3 \\
\hline
\end{tabular}

The two indexes under the expansibility index are geographic information system expansion and network virtual reality expansion. The judgment matrix, relative weight and hierarchy are shown in the table.

Table 6 Indicators of extensibility criteria 
$(C I=0.00<0.1$, meeting the requirements of consistency test)

\begin{tabular}{ccccc}
\hline Expansibility & $\begin{array}{c}\text { Geographic Information } \\
\text { System (remote } \\
\text { sensing) extension }\end{array}$ & $\begin{array}{c}\text { Expansion of } \\
\text { network virtual } \\
\text { reality }\end{array}$ & $\begin{array}{c}\text { Relative } \\
\text { weight }\end{array}$ & $\begin{array}{c}\text { Hierarchical } \\
\text { sorting }\end{array}$ \\
\hline $\begin{array}{c}\text { GIS extension } \\
\text { Expansion of network } \\
\text { virtual reality }\end{array}$ & 1 & 3 & 0.750 & 1 \\
\hline
\end{tabular}

According to the results of single ranking of the above levels, the whole model is sorted. The total sorting results are shown in the table.

Table 7 Evaluation and comparison of the effect of landscape pattern reconstruction

\begin{tabular}{ccc}
\hline index & Relative weight & Hierarchical sorting \\
\hline fast & 0.484 & 1 \\
accuracy & 0.097 & 3 \\
visual quality & 0.160 & 2 \\
Optical quality & 0.022 & 9 \\
Acoustic quality & 0.024 & 8 \\
The motion properties of human simulator & 0.076 & 4 \\
Physical expression of garden elements & 0.010 & 11 \\
Types of simulated garden elements & 0.027 & 7 \\
How easy it is to master & 0.037 & 5 \\
Interface and upgrading capability & 0.010 & 11 \\
How fast to create a virtual scene & 0.004 & 5 \\
GIS extension & 0.037 & 10 \\
Expansion of network virtual reality & 0.012 & 13 \\
\hline
\end{tabular}

According to the ranking results of each index shown in the table, we can see the relative importance of each index. It can be seen that the quickness under the interaction criterion is the most important evaluation index, and the second important is the authenticity of authenticity. In this way, we can determine the first factors to be considered in the evaluation. According to the determined evaluation index, the hierarchical structure as shown in the figure is established.

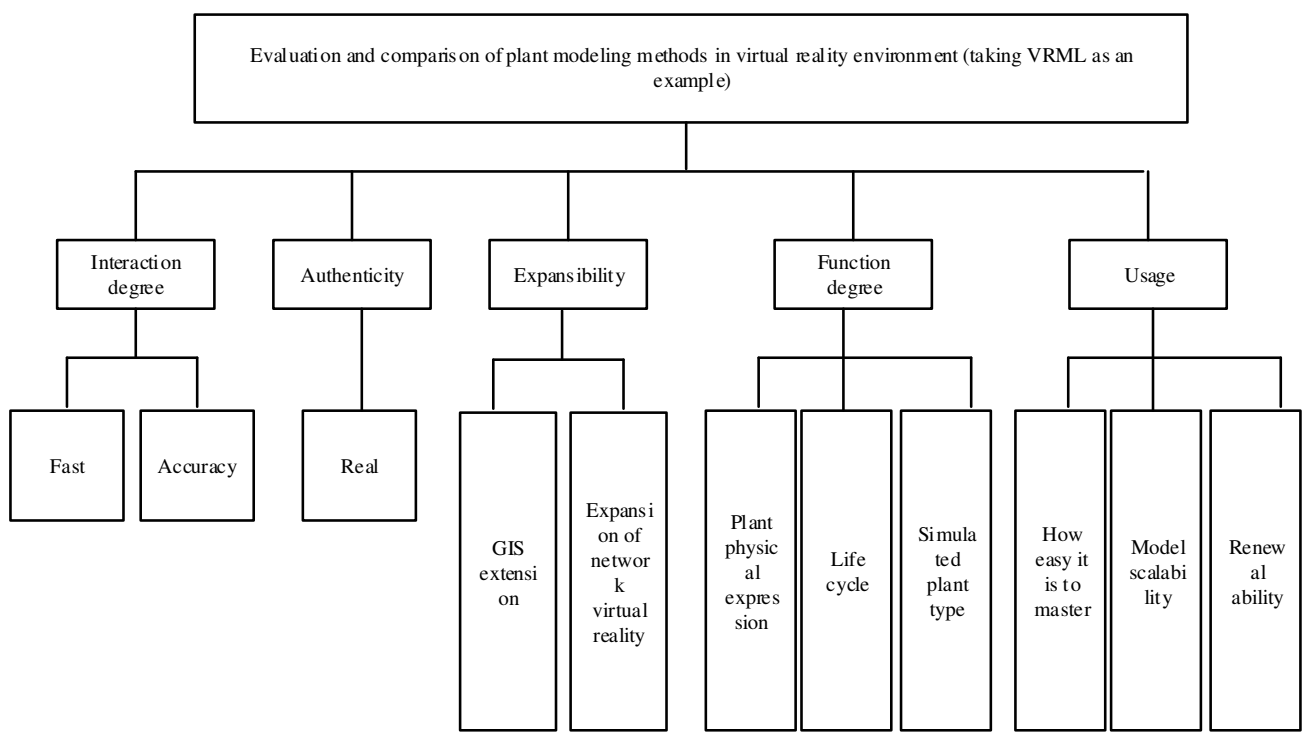

Fig. 4 landscape evaluation of landscape architecture pattern setting 
The judgment matrix, relative weight and hierarchical ranking of each criterion relative to the overall objective are shown in the table.

Table 8 Criteria of evaluation objectives (CI $=0.1$, basically meeting the requirements of consistency test)

\begin{tabular}{cccccccc}
\hline evaluate & $\begin{array}{c}\text { Usa } \\
\text { ge }\end{array}$ & $\begin{array}{c}\text { Expans } \\
\text { ibility }\end{array}$ & $\begin{array}{c}\text { Interaction } \\
\text { degree }\end{array}$ & $\begin{array}{c}\text { Interaction } \\
\text { degree }\end{array}$ & $\begin{array}{c}\text { Function } \\
\text { degree }\end{array}$ & $\begin{array}{c}\text { Relative } \\
\text { weight }\end{array}$ & $\begin{array}{c}\text { Hierarchi } \\
\text { cal } \\
\text { sorting }\end{array}$ \\
\hline Interaction degree & 1 & 3 & 7 & 6 & 5 & 0.475 & 1 \\
Interaction degree & $1 / 3$ & 1 & 5 & 4 & 3 & 0.291 & 2 \\
Function degree & $1 / 7$ & $1 / 5$ & 1 & $1 / 3$ & $1 / 5$ & 0.125 & 3 \\
Usage & $1 / 6$ & $1 / 4$ & 3 & 1 & $1 / 5$ & 0.037 & 5 \\
Expansibility & $1 / 5$ & $1 / 3$ & 5 & 5 & 1 & 0.072 & 4 \\
\hline
\end{tabular}

The two indexes under the criterion of interaction are fast and accurate, and their judgment matrix, relative weight and hierarchy are shown in the table.

Table 9 Indicators of interaction criterion

$(\mathrm{CI}=0.00<0.1$, meeting the requirements of consistency test $)$

\begin{tabular}{ccccc}
\hline Interaction degree & fast & accuracy & Relative weight & Hierarchical sorting \\
\hline fast & 5 & 1 & 0.833 & 1 \\
accuracy & 1 & $1 / 5$ & 0.167 & 2 \\
\hline
\end{tabular}

The index under the criterion of authenticity is authenticity, and its judgment matrix, relative weight and hierarchical ranking are shown in the table.

Table 10 Criteria for authenticity

( $C I=0.00<0.1$, in conformity with the requirements of conformance test)

\begin{tabular}{cccc}
\hline Authenticity & real & Relative weight & Hierarchical sorting \\
\hline real & 1 & 1 & 1 \\
\hline
\end{tabular}

The three indicators under the criterion of functional degree are plant physical expression, life cycle and simulated plant type, and their judgment matrix, relative weight and hierarchical ranking are shown in the table.

Table 11 Indicators of functional criteria $(\mathrm{CI}=0.04<0.1$, meeting the requirements of consistency test)

\begin{tabular}{cccccc}
\hline $\begin{array}{c}\text { Function } \\
\text { degree }\end{array}$ & $\begin{array}{c}\text { Plant physical } \\
\text { expression }\end{array}$ & Life cycle & $\begin{array}{c}\text { Simulated } \\
\text { plant type }\end{array}$ & $\begin{array}{c}\text { Relative } \\
\text { weight }\end{array}$ & $\begin{array}{c}\text { Hierarchical } \\
\text { sorting }\end{array}$ \\
\hline $\begin{array}{c}\text { Plant physical } \\
\text { expression }\end{array}$ & 1 & 3 & 5 & 0.105 & 3 \\
$\begin{array}{l}\text { Life cycle } \\
\text { Simulated } \\
\text { plant type }\end{array}$ & $1 / 3$ & 1 & 3 & 0.258 & 2 \\
\hline
\end{tabular}

The three indicators under the usage index are the difficulty degree, model scalability and updating ability. The judgment matrix, relative weight and hierarchy sorting are shown in the table.

Table 12 Indicators of usage criteria

(CI $=0.06<0.1$, meeting the requirements of consistency test)

\begin{tabular}{cccccc}
\hline \multirow{2}{*}{ Usage } & How easy it is & Model & Renewal & Relative & Hierarchical \\
& to master & scalability & ability & weight & sorting \\
\hline
\end{tabular}




\begin{tabular}{cccccc}
\hline $\begin{array}{c}\text { How easy it is } \\
\text { to master } \\
\text { Model }\end{array}$ & 1 & 5 & 7 & 0.072 & 3 \\
$\begin{array}{c}\text { scalability } \\
\text { Renewal } \\
\text { ability }\end{array}$ & $1 / 5$ & 1 & 3 & 0.279 & 2 \\
\hline
\end{tabular}

The two indexes under the expansion index are GIS expansion and network virtual reality expansion, and their judgment matrix, relative weight and hierarchical ranking are shown in the table.

Table 13 Expansion Criteria Indicators

(CI $=0.00<0.1$, conforming to consistency test requirements)

\begin{tabular}{ccccc}
\hline Expansibility & $\begin{array}{c}\text { Geographic Information } \\
\text { System (remote sensing) } \\
\text { extension }\end{array}$ & $\begin{array}{c}\text { Expansion of } \\
\text { network virtual } \\
\text { reality }\end{array}$ & $\begin{array}{c}\text { Relative } \\
\text { weight }\end{array}$ & $\begin{array}{c}\text { Hierarchic } \\
\text { al sorting }\end{array}$ \\
\hline $\begin{array}{c}\text { GIS extension } \\
\begin{array}{c}\text { Expansion of network } \\
\text { virtual reality }\end{array}\end{array}$ & 1 & $1 / 3$ & 0.750 & 1 \\
\hline
\end{tabular}

\subsection{AI reconstruction of landscape architecture planning pattern}

AI reconstruction design of landscape architecture involves many concepts, complex genealogy, numerous software, immature software platforms often cause compatibility problems due to format failure, and various components fail to develop harmoniously. The old process has not been thoroughly digested, and new ideas and methods are not fully developed, which makes people unable to follow, and brings many methods and technologies to study and master Difficulties. The concept genealogy described in the previous article involves many AI reconstruction design methods and technologies. Each method and technology has the commonly used software platform. In order to show the process and operation mode of AI reconstruction design of landscape architecture more clearly, a practical and expanding flow chart of landscape architecture $\mathrm{AI}$ reconstruction design is needed as a reference for the practice of $\mathrm{AI}$ reconstruction design. For landscape design, from the planning of the project to the generation of the general planning, to the location of the landscape node and the design of the single, it is divided into three basic stages, and different design scales include different links. "Coupling" is to select appropriate projects according to different environmental conditions and then introduce them into landscape architecture. This is aimed at the planning link in current planning and design. The second link corresponds to the overall planning, that is, the formation of the general plan, which is to select the appropriate environment to support the different projects. The third is to control a single project, including such control elements as the scale, coverage, volume, height and construction intensity of the building, namely the level of detailed control in planning and design. Therefore, the three links of coupling method correspond to the stage of "planning - general regulation - detailed regulation" in landscape planning and design, which covers the whole planning and design process of landscape architecture step by step. The establishment of landscape project is a planning process, which is not exactly the same as the current tourism planning. Considering the market, it also needs to combine the basic concept of AI reconstruction, and establish the content and location of the landscape project based on the field research. The planning requirements are forward-looking. In the design of landscape projects, we need to judge the possible recreational 
contents from the landscape architecture. In other words, planning needs to find out the causal relationship between things, and provide support and basis for decision-making. Accordingly, the planning of landscape projects is not a simple or airborne concept, but it is necessary to seek the basis for the existence of the project from the landscape architecture, that is, to study the relationship between the project and the environment based on coupling relationship. The so-called "coupling of project and landscape architecture" refers to the proper project in the appropriate area of landscape architecture. The establishment of the project in the scenic environment needs to consider the relevant guiding requirements such as upper level planning and government policies, and take into full consideration the tourism factors, including the demand of tourism market, the number of tourists and the target population. Not only that, the culture contained in landscape architecture is an important basis for the establishment of project content. Landscape projects are not "wood without original", and not "passive water", and the projects growing in landscape architecture are more reasonable and sustainable. The design partition can be determined by classifying the items selected based on coupling method from the function and location, and combining the qualitative and quantitative analysis of the traffic and natural resources obtained after the full investigation of landscape architecture. This is the coupling between the project and the specific area. The project not related to a specific area is meaningless. Otherwise, the ring needs to be reconstructed on a large scale The environment can meet the requirements of the project on the environment. Based on this, the impact indicators of landscape planning pattern reconstruction are planned, as shown in the following figure:

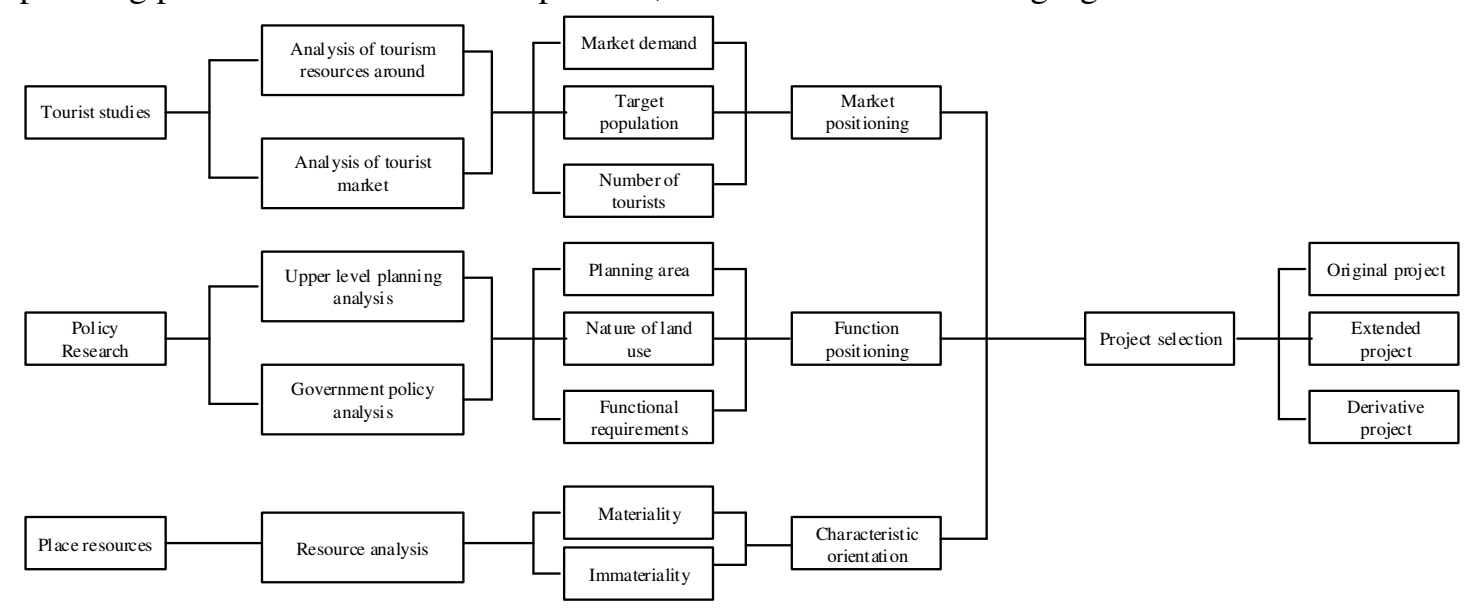

Fig. 5 Impact indicators of landscape architecture planning pattern reconstruction

Based on the research and analysis of the elements of landscape architecture, the process of coupling the design elements and landscape architecture. This process is the further deepening work after the establishment of the planning area, and also the preliminary formation process of the general plan. The coupling of elements and landscape architecture is to establish the corresponding relationship between the specific projects established in the coupling process of the upper level and the specific landscape architecture, which is also the establishment of the specific location of the project.

In order to minimize the influence of external factors on the received signal in the process of reconstructing information and obtain the above corresponding relationship in time, interleaving technology in wireless communication technology is adopted. The 456 bit coded data block of every $20 \mathrm{~ms}$ voice data frame or control information frame is divided into eight 57 bit sub blocks, 
and these eight sub blocks are respectively placed in eight continuous TCH time slots. If a burst data block is affected by interference or fading, channel coding can still ensure that enough information is received correctly through error correction. On this basis, according to the special requirements and constraints of different elements of site selection, the corresponding landscape factors are selected for superposition and evaluation, and finally the counterpoint relationship between the site and the project is established according to local conditions.

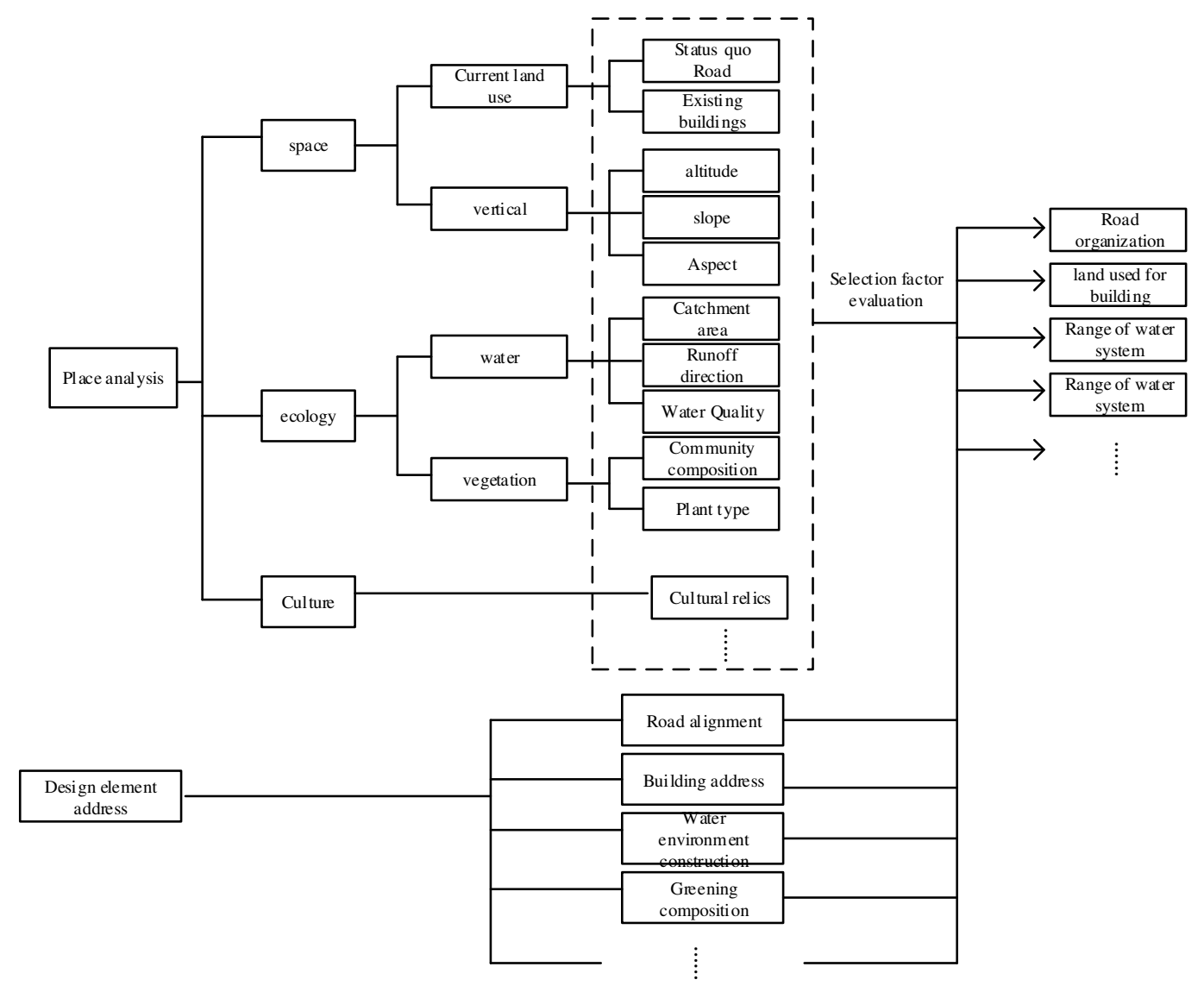

Fig.6 The coupling diagram of design elements and landscape pattern reconstruction

The design needs to clarify the coupling relationship between the main target elements and landscape architecture, such as road alignment, building location, water environment and greening. Usually, all burst data blocks belonging to a specific physical channel are transmitted with the same carrier frequency. However, if the multipath effect in the landscape is serious, the network manager can define the landscape area as a frequency hopping landscape area. At this time, slow hop is used in the landscape area to reduce the impact of multipath and interference. However, whether it is the route selection of roads or the site selection of buildings, as well as the construction of water environment are closely related to the slope, aspect, catchment and other landscape conditions, so the cognition of landscape architecture is the first step to explore the coupling relationship between design elements and landscape architecture. The research of landscape architecture should start from the space, ecology, culture and other aspects, and be subdivided into the elevation, slope, vegetation type and other basic landscape factors. Through VR technology analysis and other means and methods, fully understand the site, and complete the construction suitability, ecological sensitivity and other landscape architecture evaluation research. 
Arcvr technology and grasshopper were selected as the operation platform for reliability and validity analysis of refactoring analysis. Arcvr technology is the main operation platform of reconfiguration analysis at present, which has complete data processing function. Therefore, the reconstruction results are compared as the standard. The node visual programming mode of $\mathrm{G}$ can clearly deconstruct the data recording and processing system, its steps are intuitive and concise, and the programming gives more possibilities to the analysis process. It is necessary to write all the programs of data import, processing, reconstruction and visualization. Because of the high time cost of programming and debugging, it is positioned as an exploratory reconstruction analysis platform, and the realization of its function depends on the compilation of related programs. In the same way, although it can not be used for data analysis, its layer mixing mode is diverse, so it is positioned as an alternative thematic map reconstruction platform.

Table 14 Operation platform summary of landscape architecture reconstruction analysis multiple research

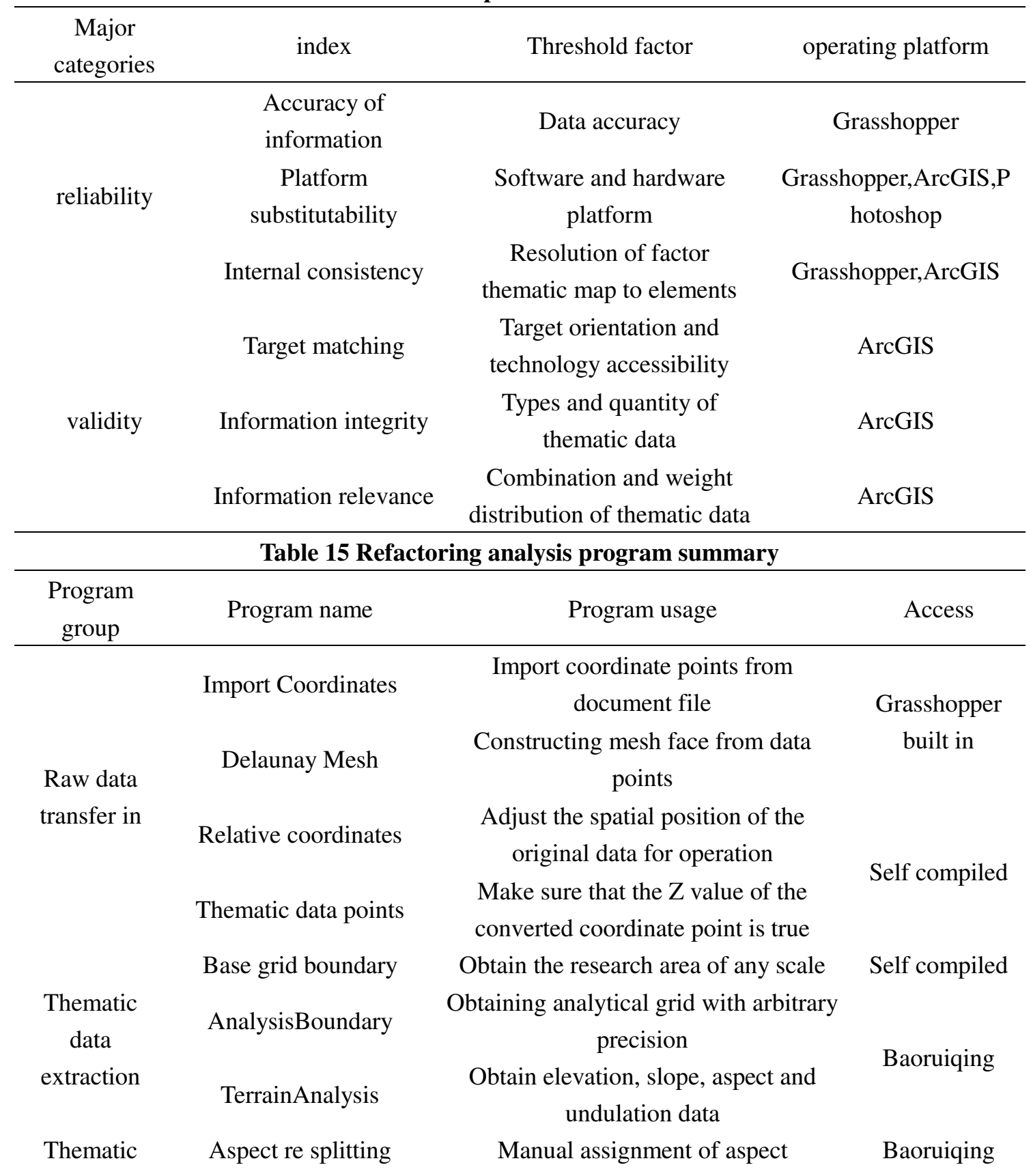




\begin{tabular}{|c|c|c|c|}
\hline \multirow[t]{3}{*}{$\begin{array}{c}\text { data } \\
\text { processing }\end{array}$} & Reclassification & $\begin{array}{l}\text { Unifying dimensions of different } Z \\
\text { values }\end{array}$ & \multirow{4}{*}{ Self compiled } \\
\hline & $\begin{array}{c}\text { Condition } \\
\text { determination }\end{array}$ & $\begin{array}{l}\text { Filter the } \mathrm{Z} \text { value of data points that } \\
\text { meet the requirements }\end{array}$ & \\
\hline & Suitability rating & $\begin{array}{c}\text { The data points after re classification } \\
\text { were evaluated }\end{array}$ & \\
\hline & Weight superposition & Data points after overlay evaluation & \\
\hline Data point & Data point visualization & $\begin{array}{l}\text { Assign a specific color to the } \mathrm{Z} \text { value } \\
\text { of the data point }\end{array}$ & Self compiled \\
\hline visualization & Legend & Display legend and color level & $\begin{array}{l}\text { Grasshopper } \\
\text { built in }\end{array}$ \\
\hline
\end{tabular}

On the one hand, it depends on the goal orientation of landscape architecture planning and design; on the other hand, it depends on the data processing methods that can be provided by the technical conditions in the same period, which is also called technical accessibility. The technology evolution process of overlay graph method shows that the three development stages are not only accompanied by the improvement of operation platform and data processing technology, but also the diversification of practice standards for reconfiguration analysis.

Table 16 Technical purpose and accessibility evolution of reconfiguration analysis in three development stages of reconfiguration method

\begin{tabular}{|c|c|c|}
\hline Development stage & Target orientation & Technology accessibility \\
\hline $\begin{array}{l}\text { A simple manual overlapping stage } \\
\text { dominated by the idea of landscape } \\
\text { resources classification }\end{array}$ & $\begin{array}{l}\text { Regional landscape } \\
\text { planning }\end{array}$ & $\begin{array}{l}\text { Direct overlay synthesis map } \\
\text { based on simple element } \\
\text { partition }\end{array}$ \\
\hline Improvement stage of overlay & Suitability evaluation & $\begin{array}{c}\text { Direct / weighted } \\
\text { superimposed synthesis map } \\
\text { based on subject classification }\end{array}$ \\
\hline suitability evaluation & $\begin{array}{l}\text { Landscape road } \\
\text { alignment }\end{array}$ & $\begin{array}{l}\text { Comparison of multiple } \\
\text { schemes based on direct / } \\
\text { weighted composite map }\end{array}$ \\
\hline \multirow{4}{*}{$\begin{array}{l}\text { The advanced stage of overlay } \\
\text { technology with computer technology }\end{array}$} & Suitability evaluation & $\begin{array}{l}\text { Weighted overlay synthesis } \\
\text { map based on geospatial data } \\
\text { processing }\end{array}$ \\
\hline & Planning site selection & $\begin{array}{c}\text { Judgment of condition } \\
\text { function based on weighted } \\
\text { superposition synthesis graph }\end{array}$ \\
\hline & $\begin{array}{l}\text { Landscape road } \\
\text { alignment }\end{array}$ & $\begin{array}{c}\text { Cost path calculation based on } \\
\text { weight superposition synthesis } \\
\text { chart }\end{array}$ \\
\hline & $\begin{array}{c}\text { Factor specific } \\
\text { analysis }\end{array}$ & $\begin{array}{l}\text { Special analysis map based on } \\
\text { geospatial data processing }\end{array}$ \\
\hline
\end{tabular}

Table 17 Processing methods of pattern planning reconstruction based on AI

\begin{tabular}{ccc}
\hline $\begin{array}{c}\text { Thematic } \\
\text { data }\end{array}$ & Data processing mode and parameter setting & $\begin{array}{c}\text { Grade evaluation of } \\
\text { weight superposition }\end{array}$ \\
\hline slope & The slope is obtained from DEM and reclassified at & The higher the slope, the
\end{tabular}




\begin{tabular}{|c|c|c|}
\hline & equal intervals of $1-10$ & higher the cost \\
\hline Aspect & $\begin{array}{c}\text { The slope aspect is obtained from DEM, and the } \\
\text { classification is carried out according to 1-10 manual } \\
\text { assignment }\end{array}$ & $\begin{array}{l}\text { N-8, ne-9, E-10, se-8, S-7, } \\
\text { sw-5, W-4, nw-6 }\end{array}$ \\
\hline Fluctuation & $\begin{array}{l}\text { The undulation is obtained from DEM, and the } \\
\text { classification is carried out according to 1-10 manual } \\
\text { assignment }\end{array}$ & $\begin{array}{l}\text { The greater the } \\
\text { fluctuation, the higher the } \\
\text { cost }\end{array}$ \\
\hline Land use & Without any processing, it is directly used for stacking & $\begin{array}{l}\text { Shrub-5, water-10, } \\
\text { wasteland-3, construction } \\
\text { area-9, agricultural land-4, } \\
\text { forest-8, wetland-10 }\end{array}$ \\
\hline $\begin{array}{l}\text { School } \\
\text { location }\end{array}$ & Campus location based on default data processing & - \\
\hline Target point & Used for cost distance and cost path calculation & - \\
\hline \multicolumn{3}{|c|}{ Table 18 Site selection data processing methods based on ArcGIS } \\
\hline $\begin{array}{l}\text { Thematic } \\
\text { data }\end{array}$ & Data processing mode and parameter setting & $\begin{array}{c}\text { Grade evaluation of } \\
\text { weight superposition }\end{array}$ \\
\hline slope & $\begin{array}{l}\text { The slope is obtained from DEM and reclassified at } \\
\text { equal intervals of } 1-10\end{array}$ & $\begin{array}{l}\text { The smaller the slope, the } \\
\text { higher the value, }>33 \% \text { - } \\
\text { restricted }\end{array}$ \\
\hline Aspect & $\begin{array}{l}\text { The slope aspect is obtained from DEM, and the } \\
\text { classification is carried out according to 1-10 manual } \\
\text { assignment }\end{array}$ & $\begin{array}{l}\text { N-8, ne-9, E-10, se-8, } \\
\text { S-7, sw-5, W-4, nw-6 }\end{array}$ \\
\hline Land use & $\begin{array}{l}\text { Without any processing, it is directly used for } \\
\text { stacking }\end{array}$ & $\begin{array}{l}\text { Shrub-5, wasteland-10, } \\
\text { construction area-3, } \\
\text { agricultural land-9, } \\
\text { forest-4, water body and } \\
\text { wetland Restricted }\end{array}$ \\
\hline road & $\begin{array}{l}\text { Euclidean distance, split again at equal intervals of } \\
\qquad 1-10\end{array}$ & $\begin{array}{l}\text { Close to the road is high, } \\
\text { otherwise it is low }\end{array}$ \\
\hline school & $\begin{array}{l}\text { Euclidean distance, split again at equal intervals of } \\
\qquad 1-10\end{array}$ & $\begin{array}{l}\text { Close to school is low, } \\
\text { otherwise it is high }\end{array}$ \\
\hline $\begin{array}{l}\text { Entertainment } \\
\text { places }\end{array}$ & $\begin{array}{l}\text { Euclidean distance, split again at equal intervals of } \\
\qquad 1-10\end{array}$ & $\begin{array}{l}\text { It is higher to be close to } \\
\text { entertainment place, } \\
\text { otherwise it is lower }\end{array}$ \\
\hline
\end{tabular}

In the stage of manual simple overlapping map dominated by the idea of landscape resource classification, reconstruction analysis is mainly used to directly guide the large-scale regional landscape planning. Limited by the technical conditions and the lack of relevant theories at that time, the reconstructed comprehensive map can only represent the size, location, shape and other attributes of landscape elements, and does not involve the data processing, landscape suitability evaluation led reconstruction In the stage of mechanism improvement, the reconstruction mechanism is gradually improved by mchag and Hopkins, and the concept of "value" under the unified standard is given to different landscape elements, which can be regarded as the rudiment of re classification, and further defined as suitability evaluation category and landscape road route 
selection in the direction of daily standard. In the advanced stage of overlay technology, the improvement of reconstruction analysis is mainly reflected in landscape information digitization, data management, data processing methods and efficiency. The built-in modules and extensions of arcvr technology not only make the thematic data processing and comprehensive drawing more rigorous and efficient, but also directly screen out the most suitable path or construction address through condition function, cost path and other tools. At the same time, the specific landscape elements can be analyzed, so as to more specifically match the goal of landscape planning and design. From this we can draw the following conclusion: with the continuous development of refactoring analysis in both theory and technology, its goal matching presents a rising trend, specifically for each goal, there are clear analysis tools or operation steps corresponding to it. The application scope of the reconstructed comprehensive map becomes wider, which can be used as the final result to guide the land use layout, and can also be used as the basis for planning site selection and landscape road route selection. Therefore, the reconfiguration analysis of the operation platform can be used to efficiently solve the problems of site selection and landscape road route selection derived from the special factor analysis and suitability evaluation, while the target matching of other problems needs to be further verified. In order to prove the rationality of the proposed AI reconstruction of landscape architecture and the effectiveness of AI reconstruction simulation judgment method, it is necessary to design experiments to verify. Under the environment of Windows 8, the AI reconstruction model analysis platform of landscape distribution rationality is constructed. Since pointgrey flea 2 camera has a resolution of 640 pix 520 PI, 60 images provided by Landscape Architecture Association are selected as experimental data. The simulation points are analyzed according to the assigned image features, and the rationality of landscape AI reconstruction is judged based on the analysis results. Collect data in the landscape environment, and analyze the reconstruction rate of the traditional method and this method, as shown in the figure.

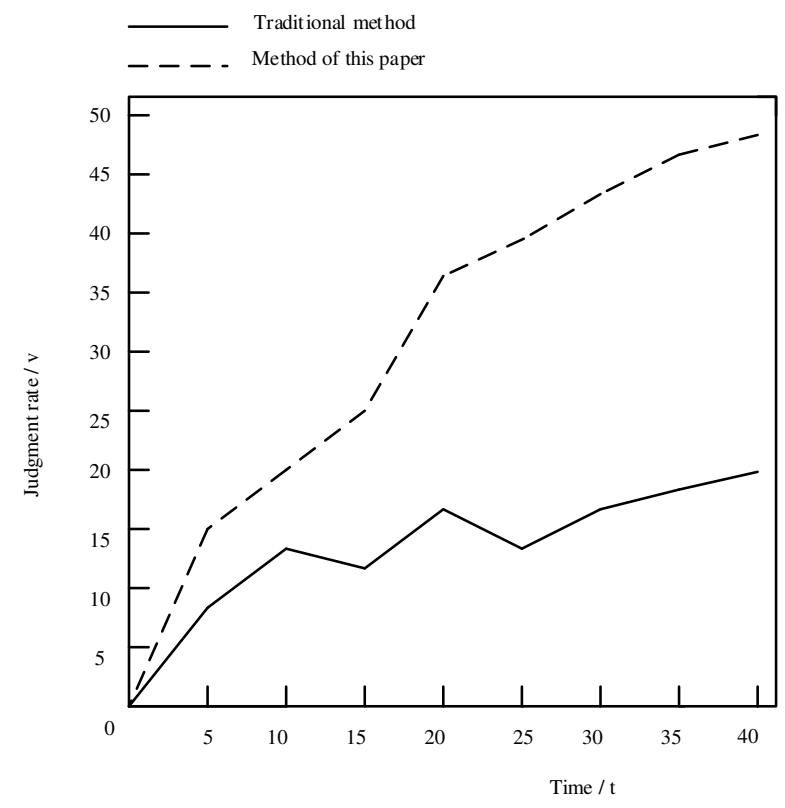

Fig. 7 Comparison results of reconstruction rate between two methods

It can be seen from the figure that: when the time is $0-10$, the reconstruction rate of traditional method increases gradually, but it is always less than that of 3D simulation method; 
when the time is $10-15$, the reconstruction rate of traditional method begins to decline. In the follow-up time, the traditional method has been floating up and down, and the fastest rate is only about half of the fastest rate of AI reconstruction simulation judgment. It can be seen that the traditional method is slower and slower in judging the rationality of landscape, while the AI reconstruction simulation method is faster. The comparison results of judgment accuracy are shown in the figure.

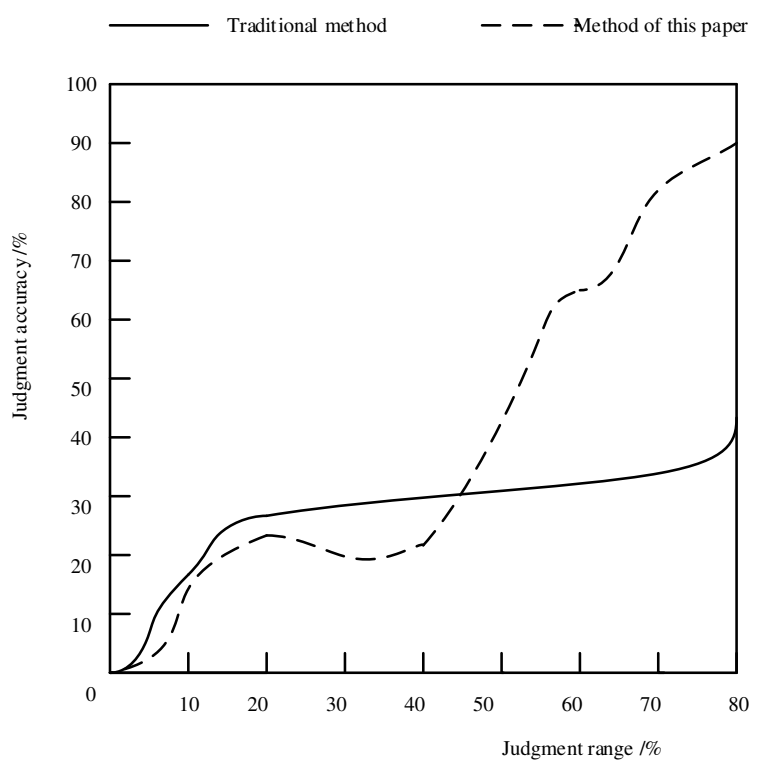

Fig. 8 Accuracy comparison results of two methods

It can be seen from the figure that: when the judgment range is less than $20 \%$, the judgment accuracy of the traditional method and this method for AI reconstruction rationality is similar, and the judgment accuracy of the traditional method is higher than that of this method; when the judgment range is $20 \%-45 \%$, the judgment accuracy of the traditional method is significantly higher than that of this method. However, with the gradual expansion of the scope, the accuracy of the AI reconstruction simulation judgment method used in this paper is gradually improved, while the traditional method is always maintained at about 40 . Therefore, the simulation judgment method based on AI reconstruction is more accurate than the traditional method. In the two experimental areas, 200 respondents were selected randomly, including 100 in the experimental group and 100 in the control group.

Table 19 Comparison of tourist satisfaction

\begin{tabular}{ccccc}
\hline project & $\begin{array}{c}\text { Number of very } \\
\text { satisfied tourists / } \\
\text { (person) }\end{array}$ & $\begin{array}{c}\text { Number of basically } \\
\text { satisfied tourists / } \\
\text { (person) }\end{array}$ & $\begin{array}{c}\text { Number of } \\
\text { dissatisfied tourists / } \\
\text { (person) }\end{array}$ & Satisfaction \\
\hline $\begin{array}{c}\text { experience } \\
\text { group } \\
\text { control } \\
\text { group }\end{array}$ & 79 & 18 & 3 & $97 \%$ \\
\hline
\end{tabular}

According to the analysis table, the number of tourists in the experimental group and the control group showed a decreasing trend. According to the longitudinal observation table, the number of tourists in the experimental group was higher than that in the control group in terms of very satisfied and basically satisfied, and the number of tourists in the control group was higher 
than that in the experimental group in terms of dissatisfaction. The satisfaction of the experimental group was $79 \%$, which was much higher than $46 \%$ of the control group. To sum up, with the implementation of the new landscape plant ecological landscape configuration method, tourists recognition of the ecological environment in the park has been continuously improved, greatly enhancing the attraction level of the landscape ecological landscape to tourists.

\section{Conclusions}

Landscape architecture is an old and young discipline. Landscape planning and design is a creative act of combining science and art. Today, with the increasingly complex environment system of human settlements, facing the challenges of ecological environment deterioration, unbalanced regional development, destructive high-speed urbanization and urban recession in the post industrial era, landscape architecture should undertake more arduous and long-term responsibilities. To continue to stick to the tradition can only make landscape architecture lose its discourse right to deal with the future and its disciplinary status. Therefore, we must actively expand our horizons, expand our influence, and absorb new knowledge system in order to maintain the strong and fresh vitality of landscape architecture.

The coming of information age and digital age is a new leap of human wisdom after the industrial age, and also a great opportunity for the development of landscape architecture. Wireless communication methods and technologies enable landscape planning and design to have the ability to scientifically, objectively and rationally understand and analyze the operation and development rules of things, and make it evolve from traditional manual operation to systematic and information-based modern design logic construction and design media expression, so that landscape planning and design and practice have a level of dialogue and common progress with related disciplines, which has the potential to meet the future The ability to challenge. Therefore, digital road is the only way of landscape planning and design. But we must also realize that wireless communication is only a wave, not a revolution, whether in the field of architecture or landscape architecture. Due to the limitations of human theory and technology, numbers can not replace the thinking of human brain. In the foreseeable future, digital strategy will still be a useful supplement to people's subjective creative behavior. Perfect digital strategy can provide us with objective analysis and unlimited possibilities, but can not make the final choice. In China, a region with rapid development and low technology level, it is impossible to fully digest and apply foreign advanced digital strategy. Therefore, before the arrival of digital wave, we should not forget ourselves and keep enough soberness and judgment. Bold innovation, but we should carefully choose the digital strategy of planning and design which is suitable for the current situation of Chinese landscape development. It will be a positive and beneficial work to explore the operation mode of digital strategy under the condition of low technology and how to combine digital strategy with regional characteristics.

\section{Conflict of interests:}

The authors declare that they have no competing interests in this section.

\section{Reference}

[1] Xiaoyu, Ai, Lu, et al. Robust Adaptive Beamforming With Subspace Projection and Covariance Matrix Reconstruction[J]. IEEE Access, 2019, 7(10):102149-102159.

[2] Mckinney C , Seibert R , Helmreich G , et al. Three-dimensional bubble reconstruction in high burnup UO2[J]. Journal of Nuclear Materials, 2020, 532(11):152053.

[3] Ai M , Yao Y, Hu Q, et al. An Automatic Tree Skeleton Extraction Approach Based on 
Multi-View Slicing Using Terrestrial LiDAR Scans Data[J]. Remote Sensing, 2020, 12(22):3824.

[4] Ghosh A, Sharma A, Chizhik A I, et al. Graphene-based metal-induced energy transfer for sub-nanometre optical localization[J]. Nature Photonics, 2019, 13(12):1-6.

[5] Ren, Xue, Lee, et al. Image reconstruction for emission tomography using intensity normalised patch-based regularisation[J]. IET Image Processing, 2019, 13(5):794-803.

[6] Zhang W , Cai A, Zheng Z, et al. A Direct Material Reconstruction Method for DECT based on Total Variation and BM3D Frame[J]. IEEE Access, 2019, PP(99):1-1.

[7] Zhao X . Application of 3D CAD in Landscape Architecture Design and Optimization of Hierarchical Details[J]. Computer-Aided Design and Applications, 2020, 18(S1):120-132.

[8] Chepurna S , Zhydkova T , Popova O . Decorative Concrete with the Addition of Highly Dispersed Organogenic Calcite (Chalk) in the Landscape Architecture of the Modern City[J]. Key Engineering Materials, 2020, 864(5):27-34.

[9] Ackerman A, Cave J , Lin C Y, et al. Computational modeling for climate change: Simulating and visualizing a resilient landscape architecture design approach[J]. International Journal of Architectural Computing, 2019, 17(2):125-147.

[10] Zahari R , Ariffin M H , Othman N . Measuring Bourdieu Capitals of Landscape Architects In Malaysian Landscape Architecture Firms[J]. Matec Web of Conferences, 2019, 266(7):06002.

[11] Washizaki H , Ogata S , Hazeyama A, et al. Landscape of Architecture and Design Patterns for IoT Systems[J]. IEEE Internet of Things Journal, 2020, PP(99):1-1.

[12] Chen C, Shi L, Lu Y, et al. The optimization of urban ecological network planning based on the minimum cumulative resistance model and granularity reverse method: A case study of Haikou, China[J]. IEEE Access, 2020, PP(99):1-1.

[13] Alam T , Reis G M , Bobadilla L, et al. A Data-Driven Deployment and Planning Approach for Underactuated Vehicles in Marine Environments[J]. IEEE Journal of Oceanic Engineering, 2020, PP(99):1-17.

[14] Liu P , Cai Z, Xie P , et al. A Decomposition-coordination Planning Method for Flexible Generation Resources in Isolated Microgrids[J]. IEEE Access, 2019, PP(99):1-1.

[15] Lahiry A . Antenna array techniques for nonuniform cell zooming and adaptive frequency planning[J]. International journal of communication systems, 2019, 32(2):e3846.1-e3846.17.

[16] Hong Y D , Lee B . Real-Time Feasible Footstep Planning for Bipedal Robots in Three-Dimensional Environments Using Particle Swarm Optimization[J]. IEEE/ASME Transactions on Mechatronics, 2020, 25(1):429-437.

[17] Anwar T , Liao K , Angelic S, et al. Inferring Location Types with Geo-Social-Temporal Pattern Mining[J]. IEEE Access, 2020, PP(99):1-1.

[18] Hong Y D , Lee B . Real-Time Feasible Footstep Planning for Bipedal Robots in Three-Dimensional Environments Using Particle Swarm Optimization[J]. IEEE/ASME Transactions on Mechatronics, 2019, PP(99):1-1.

[19] Li K , Feng M , Biswas A, et al. Driving Factors and Future Prediction of Land Use and Cover Change Based on Satellite Remote Sensing Data by the LCM Model: A Case Study from Gansu Province, China[J]. Sensors, 2020, 20(10):2757.

[20] Thien H T , Kien C V , Anh H P H . Optimized stable gait planning of biped robot using multi-objective evolutionary JAYA algorithm[J]. International Journal of Advanced Robotic Systems, 2020, 17(6):172988142097634.

[21]Wei D , Meiyun C . Reconstruction of partial envelope of interference pattern based on chirp 
Z-transform[J]. Optics Express, 2019, 27(10):13803. 


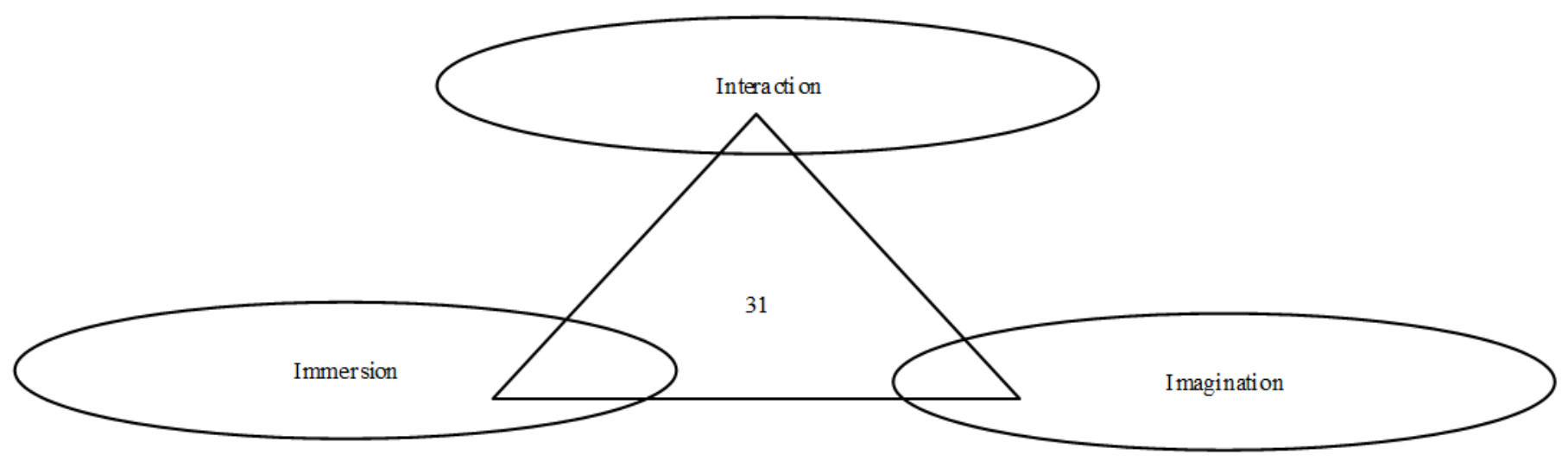

Figure 1

\section{Landscape architecture pattern planning characteristics under VR technology}

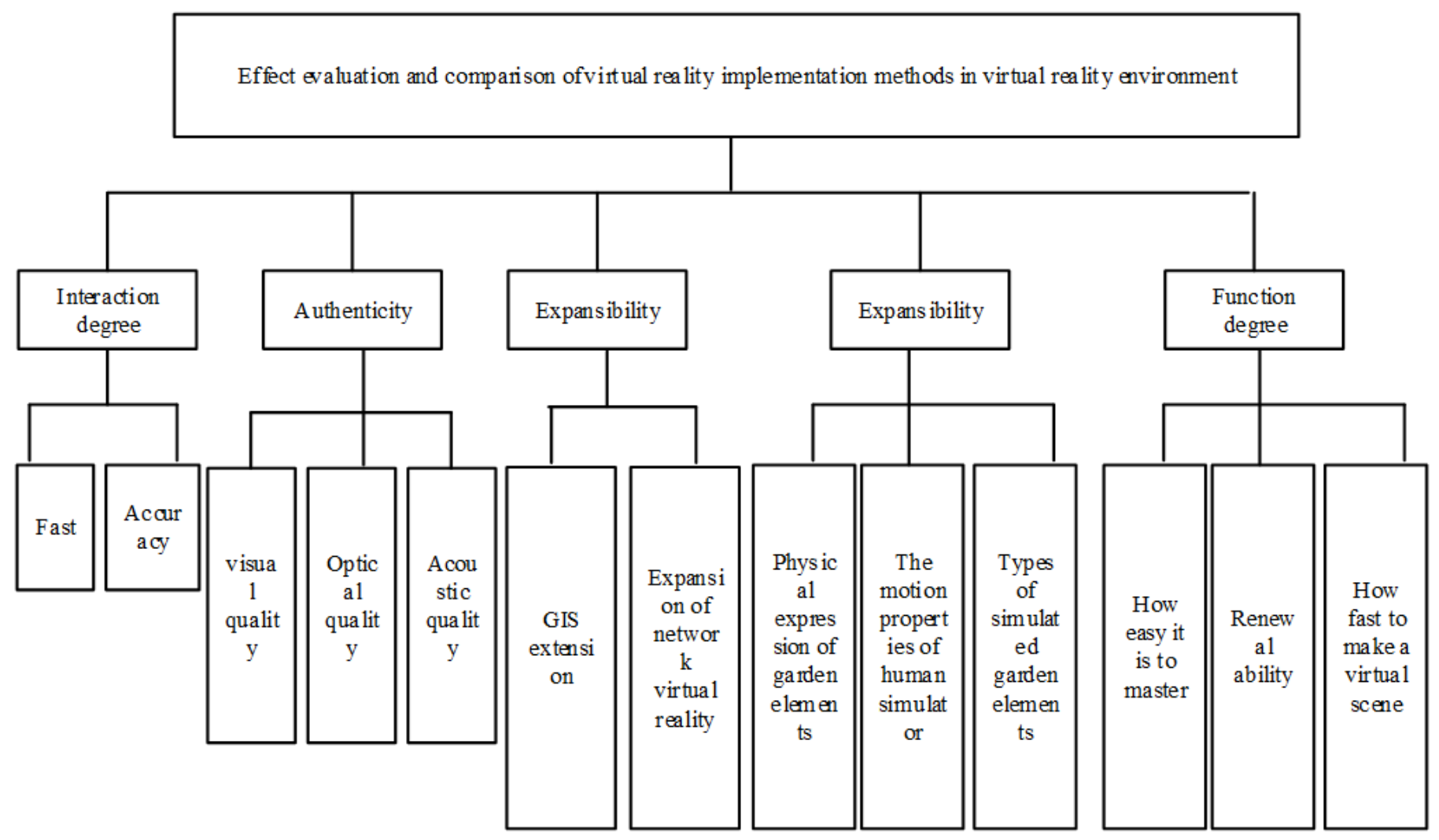

Figure 2

Hierarchical structure of landscape architecture pattern planning effect comparison 


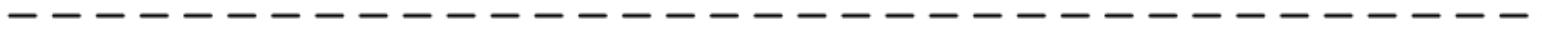

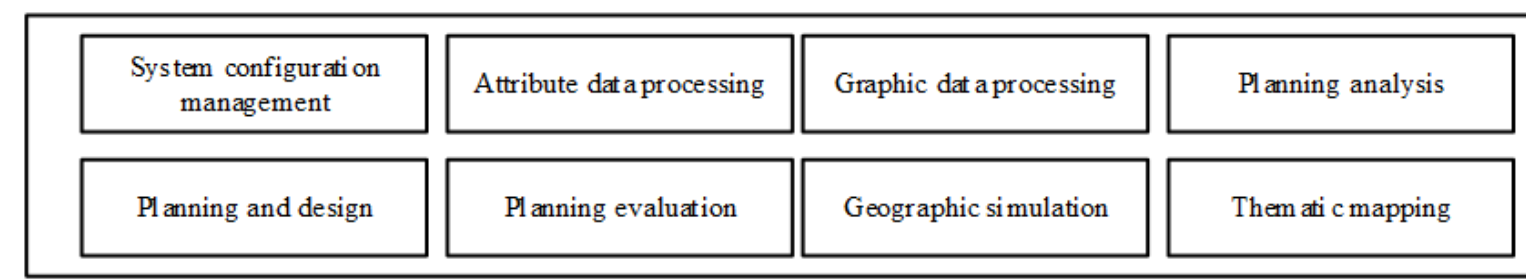

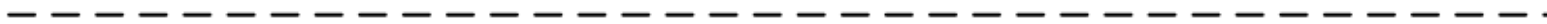

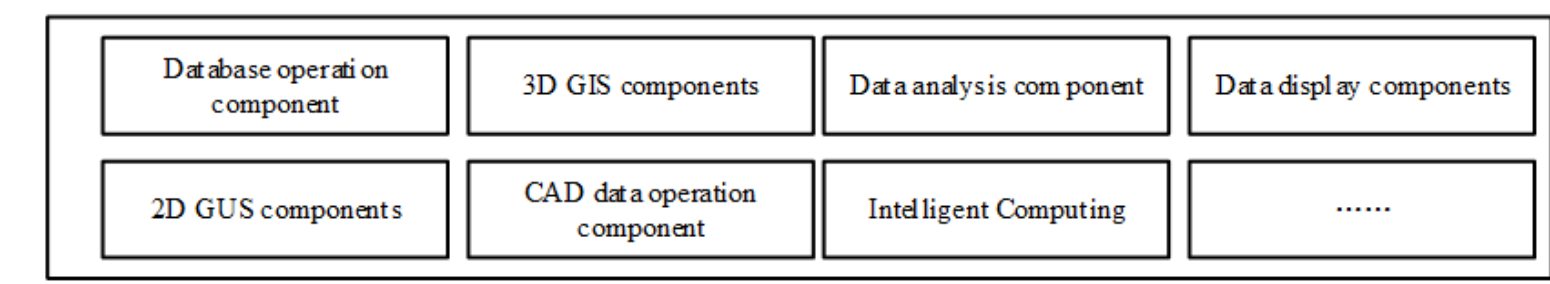

Service component layer

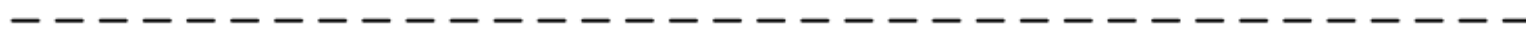
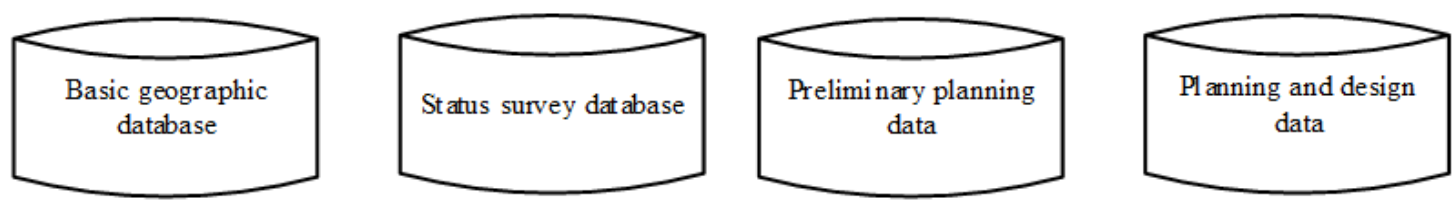

Dat abase 1 ayer

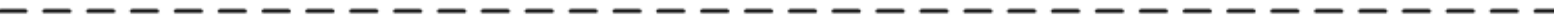

\section{Figure 3}

\section{Landscape architecture planning pattern reconstruction system}

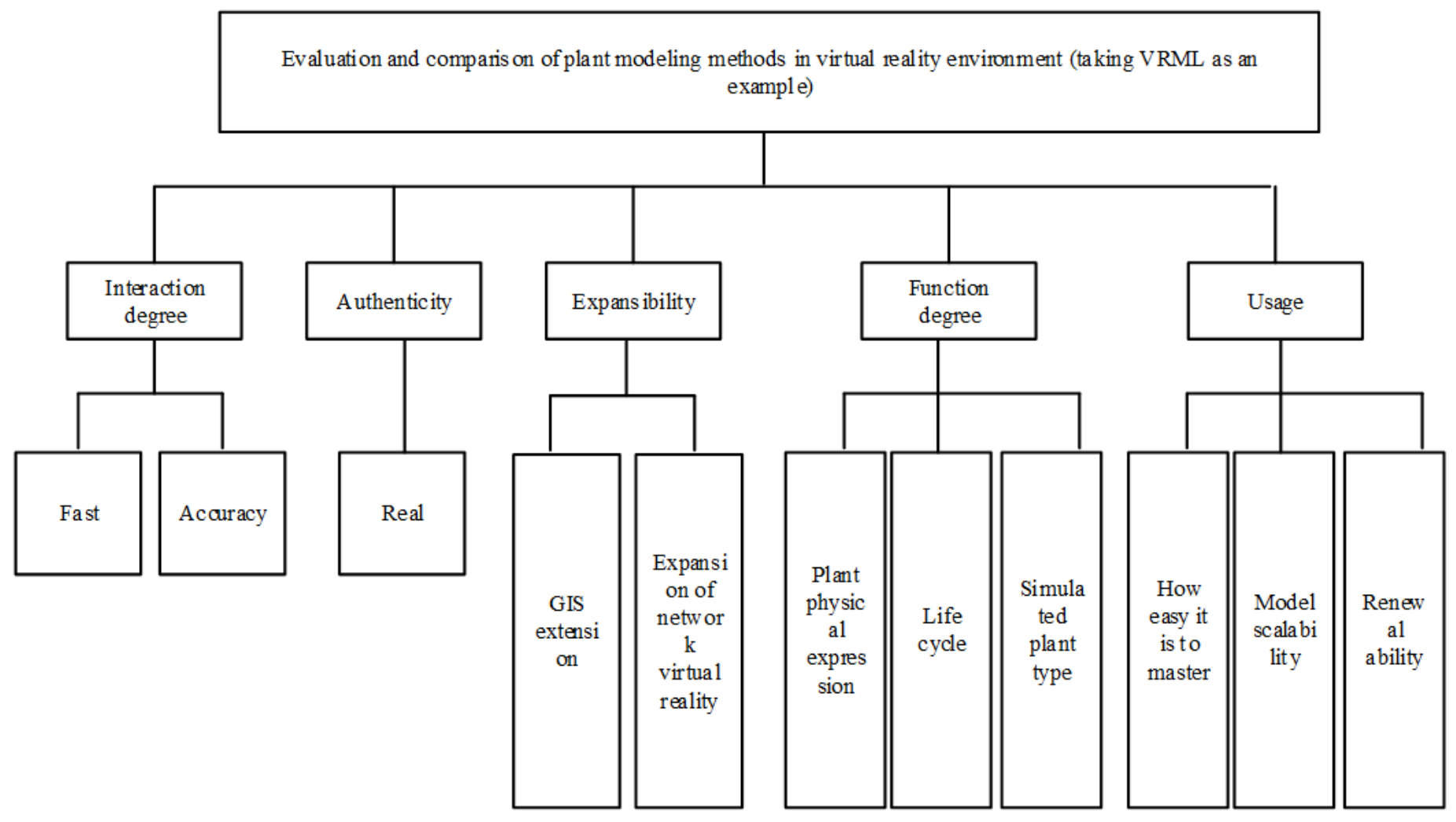


landscape evaluation of landscape architecture pattern setting

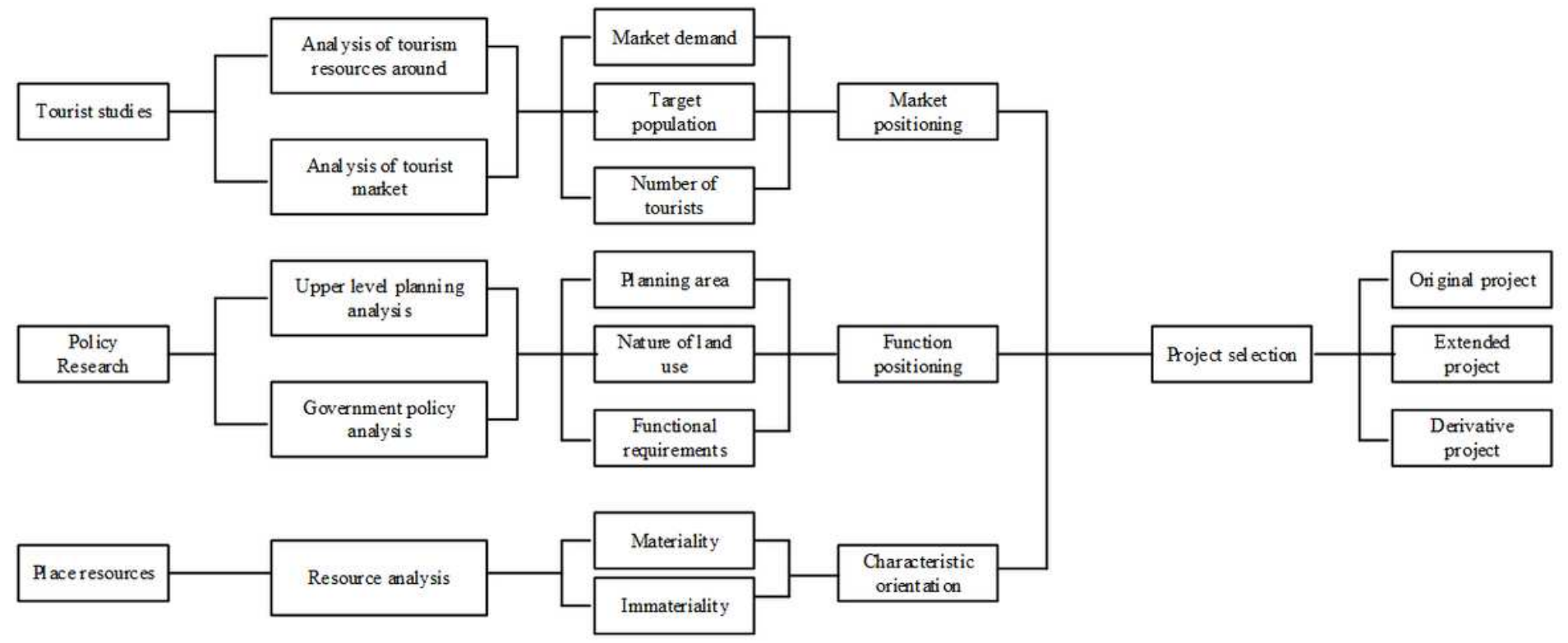

\section{Figure 5}

Impact indicators of landscape architecture planning pattern reconstruction 


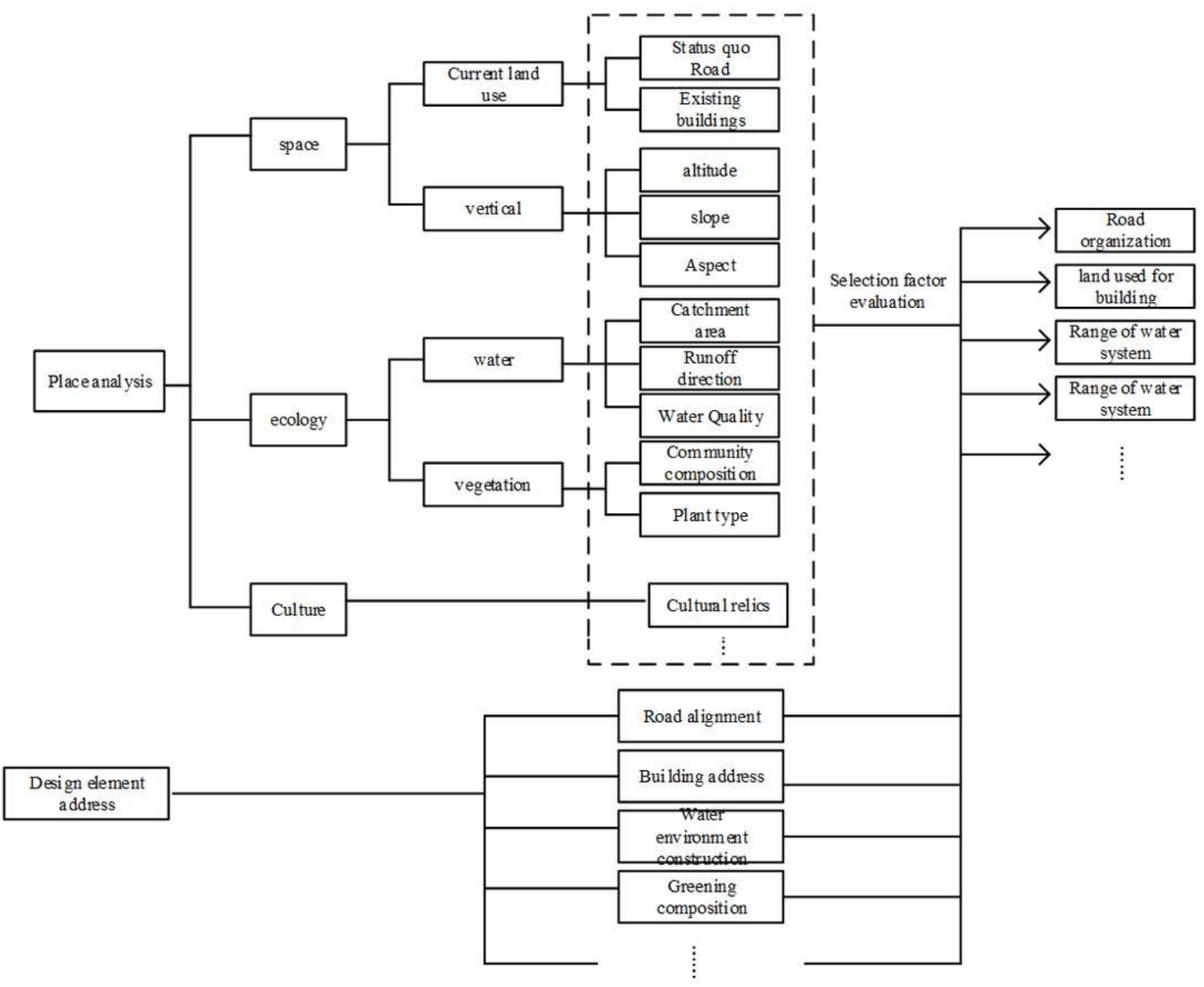

Figure 6

The coupling diagram of design elements and landscape pattern reconstruction 


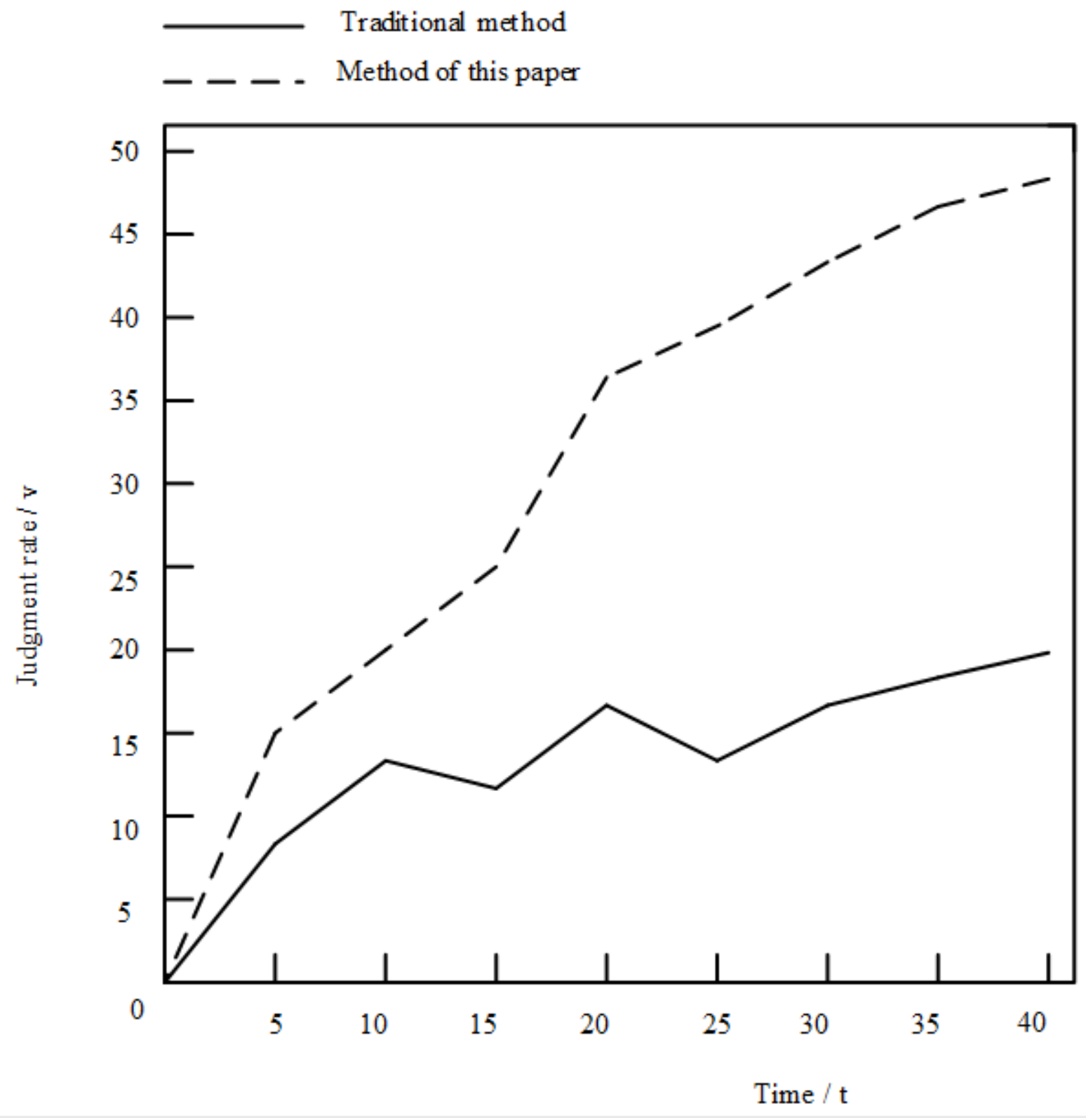

Figure 7

Comparison results of reconstruction rate between two methods 


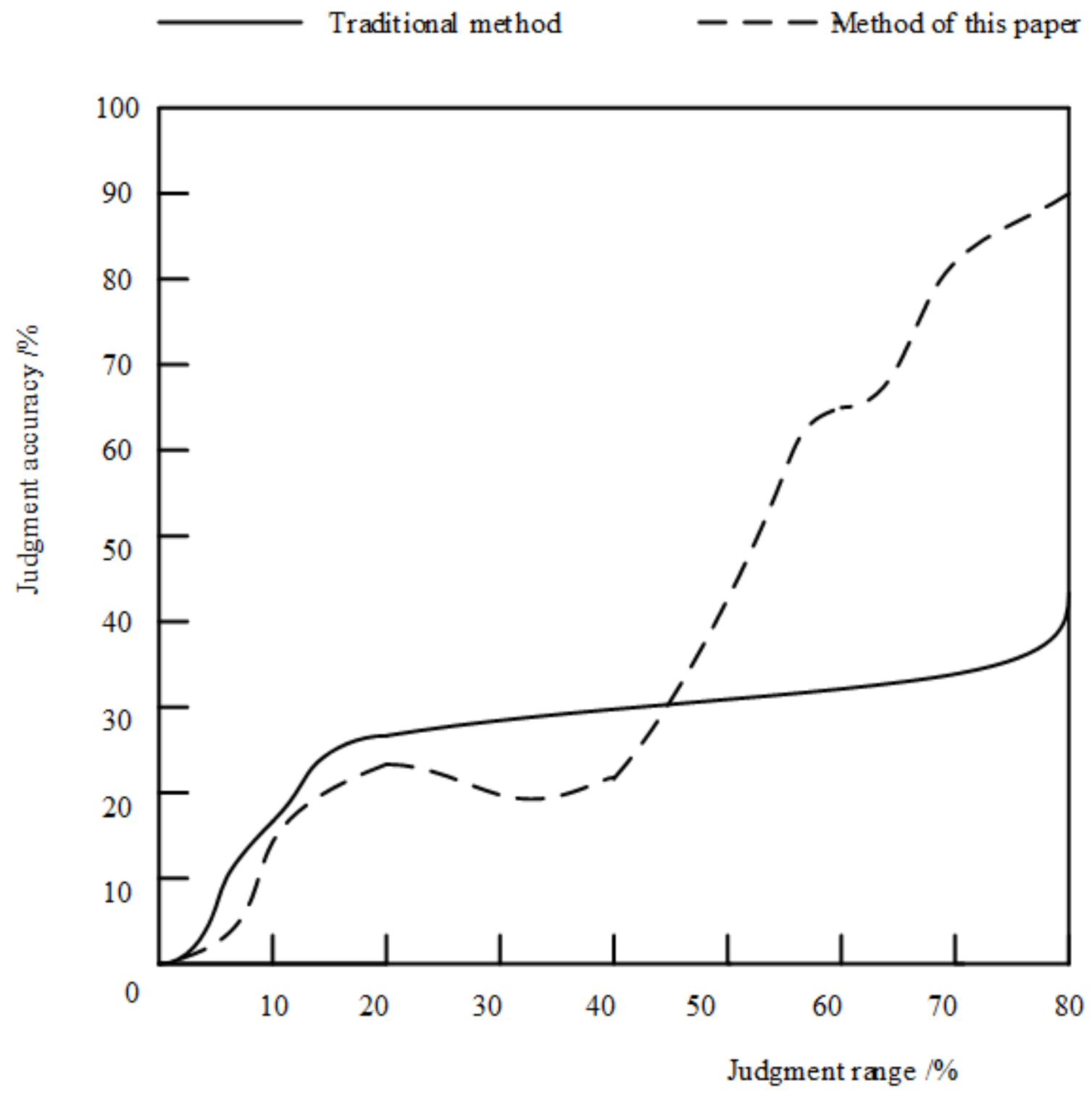

Figure 8

Accuracy comparison results of two methods 